\title{
INVENTÁRIO EXTRAJUDICIAL: ASPECTOS PRÁTICOS DA LEI N. 11.441/07
}

\author{
Alexandre Ramos Ribeiro* \\ Profa Ms Claudete de Souza**
}

\section{RESUMO}

O presente trabalho apresenta os principais tópicos do inventário extrajudicial, instituto criado pela Lei 11.441/2007 e regulamentado pela Resolução no 35, do Conselho Nacional de Justiça, realizado em Cartório, cotejando suas características, diferenças e semelhanças com o inventário judicial, procedimentotratado no Código Civil, em Direito das Sucessões e, também, no Código de Processo Civil de 2015. A temática desenvolvida abordará ainda os aspectos positivos do advento do inventário extrajudicial, das mudanças ocorridas nas leis, bem como vem sendo recepcionado pela jurisprudência dos Tribunais Superiores. Foi empreendida pesquisa doutrinária, legal e jurisprudencial, a fim de alcançarmosopiniões dos principais juristas contemporâneos a respeito desse instituto.

Palavras chave: Inventário Extrajudicial; Inventário Judicial; Partilha.

EXTRAJUDICIAL INVENTORY: PRACTICAL ASPECTS OF LAWNO. $11.441 / 07$

\section{ABSTRACT}

This paper presents the main topics of the extrajudicial inventory, an institute created by Law 11.441/2007 and regulated by Resolution No. 35 of the National Council of Justice, held in Notary Public, comparing its characteristics, differencesand similarities with the judicial inventory, a procedure dealt with in Civil Code, in Succession Law and, also, in the Civil Procedure Code of 2015. The theme developed will also address the positive aspects of the advent of the extrajudicial inventory, of the changes that occurred in the laws, as well as being received by the jurisprudence of the Superior Courts. Doctrinal, legal and jurisprudential research was undertaken in order to reach the opinions of the main contemporary jurists about this institute.

Key words: Extrajudicial inventory. Inventory. Sharing.

\section{INTRODUÇÃO}

O tema analisado neste artigo é o inventário extrajudicial, sob a perspectiva da Lei Federal 11.441, de 2007, delimitando seu alcance e o comparando com a

* Formado em contabilidade e formando em Direito pela Universidade Metodista de São Paulo. Contador: alexandre.ribeiro@contabilidaderibeiro.com.br

** Doutoranda em Educação pela Universidade Metodista de São Paulo; Mestre em Direito pela Universidade Metropolitana de Santos; Bacharel em Direito pela Faculdade de Direito de São Bernardo do Campo; Bacharel em Ciências Políticas e Sociais pela Universidade Municipal de São Caetano do Sul; Advogada. Professora Universitária. E-mail: claudete.souza@metodista.br. 
modalidade judicial, apresentando suas distinções, praticidades e repercussão no mundo jurídico.

Inventário é o instrumento disponibilizado pelo ordenamento jurídico nacional, exigido para regularizar a transmissão de uma herança deixada para os herdeiros, ao ocorrer o evento morte do autor do patrimônio. O total da herança deixado pelo de cujus (redução da expressão latina "de cujus sucessione agitur", que em tradução livre é "de quem a sucessão ocorre") recebe o nome de Montemorou espólio e é transmitido para os herdeiros, tão logo faleça a pessoa que deixou a herança, porém, só será definitivamente distribuída ao final do processo de inventário, ao realizar-se o último ato processual, que é a partilha. Assim, o inventário é o instrumento legal exigido dos herdeiros quando ocorre a sucessão, com a finalidade de receber e/ou legitimar o seu quinhão do espólio.

Para a devida elucidação do leitor, devemos explorar e pesquisar o surgimento do inventário, compreendendo suas principais características e aspectos sociais em cada época, desde as influências do Direito Romano até as nuances e mudanças ao longo do tempo até a sociedade atual, bem como os motivos que levaram ao surgimento da Lei 11.441/2007, que autoriza o inventáriona forma extrajudicial, realizado em Cartório, sempre que não haja dissenso entreos herdeiros e, também, que menores de 18 anos ou nascituros estejam envolvidos.

Ainda, aprofundando os estudos no ordenamento jurídico brasileiro e as instituições pátrias, como o Poder Judiciário e Cartórios notariais, é preciso contextualizar as leis e atos normativos que ornam o instituto do inventário para estabelecer de forma mais concisa as demandas da sociedade.

No sistema jurídico atual, a Constituição é a lei matriz para todos ospreceitos legais, como Códigos e todas as demais espécies de leis infraconstitucionais. Nesse sentindo, o Código Civil de 2002 é a Lei que normatiza todas as relações civis e, sendo ainda mais específico, também abarca as relaçõeshereditárias, o que inclui, o inventário judicial.

Por um longo período, o inventário se dava exclusivamente por meio judicial, ou seja, através do Poder Judiciário e, por ser um processo extremamente moroso, inúmeras demandas que transcendem este processo desabrocharam. O desenvolvimento do trabalho se dá pela identificação dos motivos da morosidade e inúmeras dificuldades que se encontram na realização do processo de inventáriona forma judicial, o que causa inúmeros transtornos aos herdeiros e, muitas vezes,aos terceiros interessados, geralmente credores do de cujus ou dos próprios herdeiros.

O assunto abordado, apesar de não ser tão explorado, ainda se torna atual, pois constantemente as pessoas estão optando pela realização da partilha da herança através de inventário extrajudicial, este regido pela Lei 11.441/2007.

Nossa experiência como Contador, ao longo dos anos, evidenciou a morosidade do procedimento judicial dos processos de inventário, bem como a excessiva burocracia e diversos empecilhos administrativos, extrajudiciais e, principalmente fiscais, que provocam a demora na conclusão dos processosjudiciais. Em contrapartida, a facilidade e benefícios vivenciados pela introdução do inventário extra- 
judicial contribuíram para despertar nosso interesse e ânimo para a exploração e aprofundamento deste estudo.

O que nos motivou a elaboração deste artigo, além dos problemas narrados anteriormente, é a consequência jurídica que o inventário afeta, algumas vezes, atingindo o cenário econômico e até mesmo político. Além do mais, o tema é pertinente inclusive ao mundo jurídico, no que tange o aspecto tributário que incidena transmissão da herança, ao alívio que o processo extrajudicial provoca no já embaraçado judiciário nacional e, ainda, os problemas decorrentes da carga tributária e as tentativas de "contornar os tributos", ou seja, sonegar os impostos.

Deste modo, o texto a seguir está organizado em três seções. A primeira delas, "Origem e evolução do direito sucessório" concentra-se em traçar uma concisa evolução do Direto das Sucessões desde a Antiguidade até o implementodo Código Civil de 2002.

A segunda seção, de título Inventário aborda a modalidade sucessória em todos os seus aspectos legais e suas características, fazendo uma breve distinçãoentre o inventário judicial e o extrajudicial e a terceira "Cotejamento entre Inventário Extrajudicial e Judicial" apresenta as características e praticidades da modalidade prestigiada pela pesquisa, analisando os benefícios que tal instituto apresenta para o mundo jurídico e social, demonstrando os benefícios que acrescenta sobre a modalidade de inventário judicial.

\section{ORIGEM E EVOLUÇÃO DO DIREITO SUCESSÓRIO}

Antes de tudo faz-se importante compreendermos a origem e o fundamentos do instituto da sucessão. A palavra "sucessão", em sua origem etimológica, significa, de forma abrangente, o ato pelo qual uma pessoa assume o lugar de outra, substituindo-a na titularidade, seja para bens, seja para direitos, ou ainda para ambos os casos (GONÇALVES, 2017).

Em outras palavras, sucessão significa dizer que um ou mais bens e/ou direitos foram transmitidos de uma pessoa para outra, podendo ser essa relação realizada entre vivos ou não. Como falaremos sobre inventário, o sentido adotado será estritamente a sucessão decorrente da morte de alguém, ou seja, trataremosda sucessão causa mortis.

Este é um instituto bem antigo, que sempre esteve ligado à religião ou ao legado da família, sendo que muitas vezes, ambos estavam estritamente relacionados. A despeito, podemos citar a tradição sucessória na antiguidade (porvolta dos séculos $\mathrm{V}$ a.C. a $\mathrm{V}$ d.C.), onde o filho homem (sendo este o mais velho ou não) recebia o legado (a herança) da família, para cuidar não dos bens e legados da família, no âmbito familiar, social, econômico e até mesmo religioso, setornando o chefe e sacerdote da família. Por isso, a esposa não tinha direito à herança, por conta da sucessão ser destinada inteiramente ao herdeiro primogênito.

Com a evolução do Direito e instituição de leis escritas, citamos a Roma Antiga, que instituía a absoluta liberdade ao pater famílias em que o detentor do 
poder familiar poderia dispor da herança como bem desejasse, prevalecendo a sua vontade última, através do testamento - semelhante aos dispositivos jurídicos que temos hoje.

Porém, caso não deixasse testamento, segundo a Lei, a herança seguia a ordem de sucessão entre os herdeiros classificados como: sui, agnati e gentiles, como explica Carlos Roberto Gonçalves:

\begin{abstract}
"Os heredi sui et necessarii eram os filhos sob o poder do pater e que se tornavam sui iuris com sua morte: os filhos, os netos, incluindo-se também, nessa qualificação, a esposa. Os agnatieram os parentes mais próximos do falecido. Entende-se poragnado o colateral de origem exclusivamente paterna, como o irmão consanguíneo, o tio que fosse filho do avô paterno, e o sobrinho, filho desse mesmo tio. A herança não era deferida a todos os agnados, mas ao mais próximo no momento da morte (agnatus proximus). Na ausência de membros das classes mencionadas, seriam chamados à sucessão os gentiles, ou membros da gens, que é o grupo familiar em sentido lato" (2017, p. 15)
\end{abstract}

É possível observar, neste contexto, que em alguns casos a sucessão era transmitida, mesmo sem testamento, às pessoas que não tinham necessariamentevínculos sanguíneos, como o caso da sucessão dos gentiles, que possuía uma abrangência que transcendia tal laço.

Com o passar do tempo e a com a evolução das normas jurídica, mais especificamente por meio do Código de Justiniano (século VI d.C.) é que a herançapassou a se legitimar exclusivamente pelo parentesco natural, ou seja, pelo vínculoconsanguíneo, sendo disposta a ordem de vocação da seguinte forma:descendentes; ascendentes (em concurso com os irmãos e irmãs bilaterais) em concorrência com a esposa; os irmãos e irmãs e outros parentes colaterais.

O Direito Romano foi referência e se tornou influência para a legislação sucessória que dispomos em nosso ordenamento jurídico, tomando como base a sucessão pela vocação hereditária.

Podemos perceber essas influências tanto no Código Civil vigente, como em nossa primeira Codificação Civil de 1916, que estabelecia o Direito das Sucessões no Livro IV, onde se respeitava a última vontade da pessoa falecida (de cujus). Essa vontade era positivada no próprio Código, como se vê no artigo 1.573 da referida Lei: “Art. 1.573. A sucessão dá-se por disposição de última vontade, ou em virtude da lei".

Contudo, caso não existisse a expressão dessa última vontade através do testamento, a Lei estabelecia a herança pela ordem de vocação hereditária: “Art.

1.574. Morrendo a pessoa sem testamento, transmite-se a herança a seus herdeiros legítimos. Ocorrerá outro tanto quanto aos bens que não forem compreendidos no testamento".

Sabe-se que a legislação é um reflexo dos usos e costumes da sociedade, por isso é interessante observar que o cônjuge perdia preferência na ordem de suces- 
são para os descendentes e ascendentes, o que demonstra traços dalegislação sucessória da remota ordenação romana.

Vale esclarecer aqui que a esposa, segundo a Lei, somente tinha direito relativos ao uso e fruto do bem imóvel, isso quando se possuía um único bem de família, pois, caso houvesse mais propriedades imóveis, a esposa não teria direito a herdar nada, exceto a sua cota parte havendo união universal dos bens,

Além do mais, o códex revogado fazia algumas diferenciações entre os descendentes, como entre os filhos legítimos e legitimados e, ainda, entre os filhosadotados, que tinham direitos desiguais e discriminatórios.

A legislação sucessória evoluiu e desembarca na sociedade contemporâneado século XXI respeitando, com mais adequação, as mudanças sociais, valores, usos e costumes que foram se transformando, até a disposição sucessória que temos vigente no ordenamento jurídico brasileiro.

\section{O INVENTÁRIO}

No Brasil, uma grande novidade na legislação sucessória foi sua disposição na Constituição de 1988 como uma garantia fundamental. Ter o direito de herança elevado a direito fundamental elencado que está na Lei Maior do Estado, demonstra a importância que se atribuiu à transmissão do patrimônio do de cujus àquelas pessoas de seu núcleo familiar que o sucedem.

Vimos, na sessão anterior, que até um certo patamar da história, existia ainda uma diferenciação entre algumas classes de herdeiros, como entre os filhoslegítimos, legitimados e os adotados. Contudo, a Carta de 1988 mitigou expressamente tais distinções, dispondo, em seu artigo 227 , parágrafo $6^{\circ}$, vedação, de forma clara e explícita, a qualquer discriminação ou distinção de direitos entre os filhos herdeiros, sejam eles decorrentes do casamento ou não.

Por meio dessas significativas mudanças na legislação, lenta e paulatinamente as leis infraconstitucionais foram sendo alteradas e adaptadas às ordens constitucionais de 1988, até que houve a necessidade de reestruturar todoo ordenamento civil - claro não somente por conta do direito das sucessões, maspor conta da complexidade das leis civis sendo instituído, em 2002, um novo Código Civil.

O Código Civil de 2002, em linhas simples, define a sucessão como "o processo de avaliação e liquidação de todos os bens do de cujus ao tempo de suamorte, para distribuí-los entre seus sucessores". Isso implica dizer que a sucessãotranscende o mero direito material, dependendo também de um procedimento paraser efetivado, ou seja, suas fases são observadas no Direito Processual Civil.

Tal mecanismo é tutelado pelo Poder Judiciário, meio estatal legitimado a operar a transmissão da herança com a devida solenidade, realizado por um procedimento próprio, organizado no Código de Processo Civil (CPC) (No Capítulo VI do artigo 610 ao 686). No processo de inventário, dada a sua abertura, o juiz (personalidade togada pelo Poder Judiciário para conduzir o processo judicial) desde logo nomeará um inventariante, pessoa que será responsável pela organi- 
zação e administração do espólio do de cujus até o final da divisão dos bens, que ocorre com a partilha.

O inventário, apesar de ser regido por um procedimento solene, permite que seja desenvolvido judicialmente de duas formas: pelo arrolamento de rito comum, ou arrolamento pelo rito sumário. Havendo concordância entre os herdeiros e a partilha é amigável rito sumário. No arrolamento comum não leva emconta o eventual acordo entre as partes interessados, e sim, o valor dos bens a inventariar.

Feito esses procedimentos é realizado a partilha, que é a distribuição do quinhão (fração herdada do espólio) aos respectivos herdeiros, decidida ou homologada pelo juiz, dependendo da existência de conflitos de interesse entre ossucessores ou não.

Até meados do ano de 2007, existia apenas a possibilidade de ser realizadoo inventário pela via judicial. Contudo, os processos demoravam meses, anos e até, por vezes, décadas até ser efetivamente partilhados os bens entre os herdeiros. Essa demora ocorria pela morosidade dos muitos procedimentos judiciais, além da existência de conflitos, seja entre os herdeiros, seja entreterceiros interessados, como os credores do de cujus, por exemplo, que têm interesse em receber seus créditos antes que o espólio seja distribuído entre os herdeiros necessários.

Além da demora da partilha dos bens, outro ponto negativo decorrente desses problemas incidentes no inventário judicial é a depreciação dos bens no momento da partilha pois, devido ao longo lapso temporal, muitas das vezes os bens inventariados acabam sendo depreciados, perdendo em muito o seu valor quando, enfim, ocorre a partilha.

Por conta destes motivos, os herdeiros acabavam optando pela "divisão informal" dos bens, deixando de realizar a formalização do inventário junto ao Poder Judiciário e, em muitos casos, ainda, por conta de brechas legais, os herdeiros "delapidavam" o patrimônio deixado pelo de cujus, praticandoirregularmente a venda dos bens e/ou direitos para terceiros. É sabido que o cidadão brasileiro não é afeito a observância da legalidade, principalmente quandose trata da transmissão de bens. Muito ao contrário, é afeito aos "contratos de gaveta", pratica a transmissão de bens imóveis sem nenhuma cautela jurídica, apenas assinando um papel onde estipula que está transmitindo a propriedade a uma outra pessoa que, obviamente, concorda com essa "informalidade" totalmenteirregular.

Assim, para contornar estes conflitos e, visando uma maior aderência e eficácia aos processos de inventário, o Congresso Nacional sancionou a Lei 11.441, de 2007, que possibilitou a realização de inventário e partilha pela via extrajudicial. É certo que o inventário extrajudicial é ferramenta que não pode ser utilizada por qualquer pessoa. Exige ausência de litígio quanto aos bens inventariados, e não pode ser utilizado quando existam menores envolvidos na disposição dos bens ou mulheres em período de gestação.

Aqui iniciamos o ponto principal do nosso artigo e analisaremos com mais atenção os aspectos práticos do inventário extrajudicial. 


\section{COTEJAMENTO ENTRE INVENTÁRIO EXTRAJUDICIAL E JUDICIAL}

A partir da vigência da Lei 11.441/07 o inventário extrajudicial passou a ser uma opção muito mais viável aos herdeiros que buscam maior celeridade no trâmite da partilha dos bens contidos em uma herança que, a princípio, resumem-se a um só montante indivisível, até que se opere a partilha.

Existem algumas diferenças que se estendem além do lapso temporal do procedimento judicial e extrajudicial, as quais passamos a listar num breve quadro sinótico para elucidar melhor as questões dissertadas a seguir:

\section{Quadro 1: Diferenças de Inventário Extrajudicial e Judicial}

\begin{tabular}{|c|c|c|}
\hline & Inventário Extrajudicial & Inventário Judicial \\
\hline Local de realização & Qualquer cartório de notas & $\begin{array}{l}\text { A competência do foro será determina- } \\
\text { da pelo último endereço do falecido }\end{array}$ \\
\hline $\begin{array}{l}\text { Possibilidade deficar } \\
\text { isento da cobrança de } \\
\text { custas }\end{array}$ & Não há possibilidade & $\begin{array}{l}\text { Depende da decisão do juiz, que pode } \\
\text { ou não conceder os benefícios da justi- } \\
\text { ça gratuita e, em caso positivo, isentar a } \\
\text { cobrança das taxas descritas no quadro. }\end{array}$ \\
\hline Custas & $\begin{array}{l}\text { Escritura Pública + atuali- } \\
\text { zação de certidões (óbito, } \\
\text { casamento/nascimento, ma- } \\
\text { trícula de imóveis e colégio } \\
\text { notarial) }\end{array}$ & $\begin{array}{l}\text { Taxa judiciária, taxa de procuração, for- } \\
\text { mal de partilha }+ \text { atualização de certi- } \\
\text { dões (óbito, casamento/nascimento) } \\
\text { e colégio notarial) }\end{array}$ \\
\hline $\begin{array}{l}\text { Imposto ITCMD } \\
-4 \% \text { sobre o va- } \\
\text { lor dos bens a serem } \\
\text { transmitidos }\end{array}$ & Pagamento a Vista & Possibilidade de pagamento parcelado \\
\hline ISENÇÃO do ITCMD & Depende de cada & caso e suas peculiaridades \\
\hline Prazo de Duração & $\begin{array}{l}\text { Até } 30 \text { dias, dependendo do } \\
\text { dia da entrega dos documen- } \\
\text { tos no cartório. }\end{array}$ & $\begin{array}{l}\text { Depende muito de caso a caso, se con- } \\
\text { cedido o parcelamento em } 8 \text { vezes, pra- } \\
\text { zo de duração estimado em } 11 \text { meses } \\
\text { aproximadamente, a depender de cada } \\
\text { fórum que o processo tramitará. }\end{array}$ \\
\hline
\end{tabular}

Fonte: elaborado pelo autor. 
Como se observa do quadro sinótico, são vários os pontos positivos do processo de inventário extrajudicial além do prazo de duração que é significativamente inferior ao processo judicial, existe a possibilidade em se realizarem qualquer cartório notarial, diferentemente do que ocorre no procedimento judicial, que deve tramitar, em regra, no foro último domicílio do de cujus.

Contudo, é notório que em contrapartida existe o ônus em se tratar do inventário pela via administrativa, que é o pagamento dos emolumentos cartorários, custas e o Imposto de Transmissão Causa Mortis (ITCMD), muito embora a modalidade judicial também traga despesas aos herdeiros. Isso implica dizer que os herdeiros arcarão, dependendo dos valores dos bens do de cujus, umvalor considerável de tais custos, não podendo ser aplicada a gratuidade das custas como no procedimento judicial, quando o assistido se declara vulnerável a ponto de não poder dispender desses valores sem prejudicar o seu sustento.

Ademais, existe outro ponto a ser observado, que é muito relevante. Para a requisição da abertura do inventário pela via administrativa devem ser cumpridos alguns requisitos, obrigatoriamente, são eles: i) que as partes sejam maiores e capazes; ii) que não exista testamento; iii) que haja concordância entre os herdeiros sobre a divisão dos bens e iv) que as partes sejam assistidas por um advogado. Existe uma razão jurídica para a obrigatoriedade destes pontos.

No primeiro caso não deve haver menores e/ou incapazes envolvidos no procedimento extrajudicial pois, nessas situações deve estar presente a atuação direta do Ministério Público tutelando os direitos e interesses do menor e/ou do incapaz; no segundo cenário se houver um testamento deixado pelo de cujus a partilha, via de regra, seguirá os termos testados. Na terceira circunstância, caso haja discordância entre os herdeiros, não pode o Tabelião decidir como será partilhado o espólio, pois não tem competência jurisdicional para tal, sendo esta exclusiva do juiz, nos casos de litígio. Já o último ponto foi uma imposição da Lei, visando que os direitos dos assistidos sejam assegurados nos termos e princípioslegais, como veremos melhor a seguir.

Com isso, caso esteja presente qualquer destes requisitos, não poderá ser realizado o inventário de forma extrajudicial. Por exemplo, mesmo que não exista testamento, haja concordância entre os herdeiros e assistência por parte de um advogado, caso um dos herdeiros ainda não seja maior de idade, não seria possível a abertura do inventário pela via administrativa, assim como havendo gestante herdeira.

Por conta disso, em casos como exemplificado acima, existe um conflito muito grande de interesses, pois, por mais que as partes quisessem realizar o inventário pela via administrativa, não estando presente um dos requisitos listadosna Lei, deveria a abertura ocorrer junto ao Poder Judiciário, sendo submetido a toda a morosidade do processo judicial.

A Lei 11.441/2007 trouxe expressamente o prazo para a abertura do inventário (exclusivamente na modalidade extrajudicial) e que foi recebida pelo Código de Processo Civil. 
O Código de Processo Civil de 2015, mais especificamente, em seu artigo 610, manteve a previsão do inventário judicial, nos casos em que o testamento ouinteressado seja incapaz, permitindo o inventário e a partilha extrajudiciais por escritura pública, quando todos os interessados forem capazes e concordes.

Com o advindo dessas legislações, algumas decisões judiciais foram percursoras em admitir o inventário administrativo, após o devido procedimento de abertura, cumprimento e registro judicial do testamento, como podemos notar no processo 0052432-70.2012.8.26.0100 da Sétima Vara da Família e Sucessões doForo Central Cível do Tribunal de Justiça de São Paulo, no qual o magistrado entendeu que: "desde que todos os herdeiros sejam maiores e capazes, não hajafundações entre os herdeiros testamentários e estejam todos de acordo acerca dapartilha, o inventário poderá ser feito de forma extrajudicial, nos termos do art. 2.015 do Código Civil, não sendo necessário ajuizamento de ação de inventário"

Nota-se que as alterações surgidas com essas legislações foram bem recebidas por alguns tribunais, muito provavelmente porque, além das imposiçõeslegais, o advento dessas leis possibilitou a migração de milhares de processos judiciais para as vias administrativas, o que, na prática, permite a maior efetividadedos processos, por conta da celeridade dos atos.

Ainda que o inventário extrajudicial seja um procedimento administrativo, como já vimos anteriormente, a Lei declarou a essencialidade da participação do advogado no processamento do instituto, com observância de todos os deveres, responsabilidades e princípios éticos disciplinados pelo Estatuto da Advocacia e Código de Ética e Disciplina. Mesmo que os herdeiros optem pela via extrajudicial, obrigatoriamente, serão assistidos por advogado, podendo ser comum a todos eles ou, cada um deles serem representados pelo defensor de sua confiança, nos termos do artigo 1.124-A, $\S 2^{\circ}$, do Código de Processo Civil, devendo o causídico ter sua qualificação e assinatura aposta na escritura de inventário e partilha, conforme artigo $8^{\circ}$, da Resolução $n^{\circ} 35 / 2007$, do Conselho Nacional de Justiça.

Diferentemente do processo judicial, o inventário extrajudicial, caso estejam presentes a anuência dos herdeiros, sendo todos maiores e capazes e os documentos estiverem em ordem, em poucos dias a partilha é realizada. Já no processo judicial, muitas vezes, mesmo estando toda a documentação em ordem,o tempo para expedição do formal de partilha varia de meses a anos. Isso porque,além da demanda, existe muita burocracia para se tratar um processo dentro do Poder Judiciário, por envolver andamentos dependentes do juiz, cartório, funcionários etc.

Na prática, o inventário extrajudicial precede de documentos quecomprovem a veracidade das afirmações feitas pelas partes, bem como dos bens,dívidas, créditos e obrigações arroladas, sendo eles, geralmente:

- Certidão de óbito do autor da herança;

- Documento de identidade oficial e CPF das partes envolvidas e do autor da herança;

- Certidão que comprove o vínculo de parentesco dos herdeiros; 
- Certidão de casamento do cônjuge sobrevivente e dos herdeiros casados, bem como pacto antenupcial, se houver;

- Certidão de propriedade, ônus e alienações dos imóveis, com atualização, inferior a 30 dias, e não anterior à data do óbito;

- Certidão ou documento oficial comprobatório do valor venal dos imóveis, relativo ao exercício do ano do óbito ou ao ano imediatamente seguinte deste;

- Documentos que comprovem o domínio e o valor dos bens imóveis, se houver;

- Certidão negativa de tributos municipais que incidam sobre os bens imóveis do espólio;

- Certidão negativa da Receita Federal e da Procuradoria Geral da Fazenda Nacional;

- Certidão de regularidade do Imposto de Transmissão Causa Mortis e Doação (ITCMD);

- Certidão comprobatória da inexistência de testamento;

- Certidão de Cadastro de Imóvel Rural (CCIR), se houver imóvel rural a ser partilhado;

Entretanto, há sempre que se levar em consideração cada caso em concreto, para apresentação de outros documentos que forem necessários.

Com todos os documentos em mãos, em especial a guia de recolhimento do Imposto sobre Transmissão Causa Mortis e Doação (ITCMD), escolhido o Cartório de Notas onde se processará o inventário, deve o advogado redigir uma minuta da escritura pública e apresentar ao Fisco Estadual para avaliação, funçõesque podem ser delegadas ao Tabelião.

Assim que a Fazenda Estadual concluir positivamente pela documentação, o Tabelião escolhido estará autorizado a lavrar a escritura pública, título hábil a realização dos demais atos de registro e transmissão de bens, como mencionado anteriormente. $\mathrm{O} \S 1^{\circ}$ do art. 610 do CPC estabeleceu que a escritura pública é título hábil, assentando higidez ao documento, dispensando a homologação judicial e podendo ser utilizada para qualquer ato de registro, bem como para levantamento de importância depositada em instituições financeiras.

Esta alteração da lei foi muito significativa aos herdeiros, pois permitiu que pudessem realizar qualquer ato de registro, seja das pessoas naturais ou imobiliário, bem como transferência de bens perante Detran, Junta Comercial, Registro Civil de Pessoas Jurídicas, instituições financeiras, companhias telefônicas, entre outras. Isso porque, mesmo com a permissão já respaldada na Resolução no 35/07 do $\mathrm{CNJ}\left(\operatorname{artigo} 3^{\circ}\right)$, mas na prática era frequentemente desrespeitada pelos órgãos públicos e instituições.

Destarte, a alteração encerrada pelo Código de Processo Civil de 2015 resolveu em absoluto a celeuma que ocorria principalmente com os bancos que, muitas vezes, por interpretação equivocada, se negavam e obstruíam o fornecimento de 
informações ou exigiam ordens judiciais para levantamento de valores ou outras providências, representando verdadeiro contrassenso à desjudicialização trazida pela Lei $\mathrm{n}^{\circ} 11.441$ de 2007.

Imaginando esse mesmo caso só que na esfera judicial, o processo seria levado à análise do juiz, entraria em uma fila de processos, o magistrado proferiria despacho para ou sanar algo ou dar prosseguimento ao feito, seriam diligenciadas pesquisas em diversos cartórios para averiguar a existência de testamento, abrirse-ia vista ao Ministério Público, retornaria ao juiz e assim por diante. Podemos ver, por meio desse exemplo comparativo, que o processo judicial é de longe mais moroso e burocrático do que o extrajudicial.

Outra mudança significativa promovida pela Resolução no 35/2007, do CNJ foi a liberdade de escolha do local da abertura do inventário, afastando expressamente as regras de competência do Código de Processo Civil. A Resolução supriu uma lacuna da Lei $\mathrm{n}^{\circ} 11.441 / 2007$ que foi silente quanto à regra para a escolha do local de processamento do inventário administrativo. A previsãoda abertura consta do artigo $1^{\circ}$ da Resolução que esclarece "Para a lavratura dosatos notariais de que trata a Lei $\mathrm{n}^{\circ} 11.441 / 07$, é livre a escolha do tabelião de notas,não se aplicando as regras de competência do Código de Processo Civil."

Com isso, os herdeiros ficam livres para procederem ao inventário extrajudicial onde acreditarem ser melhor, ainda que outro seja o local do falecimento ou dos bens, respeitadas apenas as regras de recolhimento do Imposto de Transmissão Causa Mortis e Doação (ITCMD que será pago no estadoonde for feito o inventário.

\section{CONSIDERAÇÕES FINAIS}

Podemos observar que o advento do inventário extrajudicial e a sua posterior regulamentação pela Resolução $n^{0} 35 / 2007$ do CNJ facilitou a solução da divisão dos bens após o falecimento do autor da herança, permitindo aos herdeiroscapazes e concordes, maior celeridade da partilha.

Com isso, pode-se analisar de forma categórica que a realização do inventário extrajudicial é uma benesse abrangente não só aos interessados, mas à sociedade, que vê seus conflitos serem solucionados de forma célere e com o uso da conciliação e, de via reflexa, o próprio Poder Judiciário é beneficiado, no tocante ao decorrente desafogamento de milhares de inventário que jurisdicionam, podendo promover assim, maior eficiência na prestação de seus serviços.

$\mathrm{O}$ advento do inventário extrajudicial possibilitou ainda, por meio dos dispositivos legais que a regulam, uma maior celeridade perante os demais órgãosresponsáveis pela transmissão dos bens do falecido aos seus respectivos descendentes, trazendo rapidez não somente no processo administrativo em si, mas também nos atos posteriores cogentes à alienação da partilha aos herdeiros.

Nesse sentido, pode-se, tranquilamente, afirmar a importância do inventário, que, além de permitir a redistribuição das riquezas do de cujus, traz garantias ao herdeiro e de forma legal, pode apropriar-se destes bens. 
Portanto, o direito de herança tem função social protegendo e perpetuandoos bens da família, garantindo o desenvolvimento dos indivíduos contendo importantes reflexos econômicos.

\section{REFERENNCIAS}

BRASIL. Código Civil: promulgada em 1 de janeiro de 1916. 1916.

BRASIL. Constituição da República Federativa do Brasil: promulgada em 6 deoutubro de 1988. 1988.

AUGUSTO, Guilherme. Inventário Judicial x Inventário Extrajudicial: vantagens e desvantagens. Vantagens e Desvantagens. 2020. Disponível em:https://jus.com.br/artigos/79062/inventario-judicial-x-inventario-extrajudicial. Acesso em: 21 ago. 2020.Corrija este espaçamento que está diferente dos demais. DIAS, Maria Berenice. Manual de direito das famílias. 11. ed. SãoPaulo: Revista dos Tribunais, 2016.

GANCEV, Tereza. Inventário Extrajudicial. 2018. Disponível em: https://jus.com.br/artigos/67500/inventario-extrajudicial. Acesso em: 21 ago. 2020.

GONÇALVES, Carlos Roberto. Direito Civil Brasileiro: Direito das Sucessões. 11. ed. São Paulo: Saraiva, 2017.

GONÇALVES, Carlos Roberto. Direito Civil Brasileiro: Direito de Família. 15. ed. São Paulo:Saraiva, 2018.

INÁCIO, Tayane de Souza. Inventário extrajudicial no enfoque de sua regulamentação pela resolução $\mathbf{n}^{\mathbf{0}} 35$ do CNJ. 2016. 50 f. Tese Doutorado -Curso de Direito, Faculdade Fibra, Anápolis, 2016.

LUDGERIO, Lenon Alves. Inventário extrajudicial: controle, fiscalização e publicidade. 2012. 85 f. TCC (Graduação) - Curso de Direito, Universidade do Sulde Santa Catarina, Palhoça, 2012.

MESTRINER, Angelo; BARROS, Giovanna Truffi Rinaldi de. Direito das Sucessões: inventário extrajudicial. Inventário extrajudicial. 2015. Disponível em:https://angelomestriner.jusbrasil.com.br/artigos/183862969/direito-das-sucessoes- inventario-extrajudicial. Acesso em: 21 ago. 2020.

OLIVEIRA, Rodrigo Corrêa da Costa; COSTA, Anahí Monte Cruz R Correa da. O inventário extrajudicial e seu processamento: breves considerações. 2011. Disponível em: https://ambitojuridico.com.br/edicoes/revista-87/o-inventario- extrajudicial-e-seu-processamento-breves-consideracoes/\#: :text=Como $\% 20$ dito $\% 20$ acima $\% 2 C \% 20 \mathrm{o} \% 20$ invent $\%$ C3\% A1rio, \%C3\%A0\%20partilha\%20entre\%20os\%20herdeiros.. Acesso em: 16 jun. 2020.

SILVA, Erica Barbosa e; BARROS, Giovanna Truffi Rinaldi de. O Novo CPC e o inventário extrajudicial: uma análise critica. 2016. Disponível em: https://www.lex.com.br/doutrina_27705383_O_NOVO_CPC_E_O_INVENTARIO_EXTRAJUDICIAL_UUMA_ANALISE_CRITICA.aspx. Acesso em: 18 jun. 2020. 
TARTUCE, Flávio. Direito Civil: Direito das Sucessões. 12. ed. Rio de Janeiro:Forense, 2019.

TAVARES, Regina Beatriz. Código Civil Comentado. 8. ed. São Paulo:Saraiva, 2012.

THAMAY, Rennan Faria Krüger. Manual de Direito Processual Civil. 2. ed. SãoPaulo: Saraiva, 2019.

TOLOMINI, Rafael Reis. Inventário extrajudicial e partilha por escritura pública. 2015. 39 f. TCC (Graduação) - Curso de Direito, Universidade do Noroeste do Estado do Rio Grande do Sul, Santa Rosa, 2015. (é necessáriotrazer o link para acesso) 